\title{
Clostridium Difficile Infection in Inflammatory Bowel Disease; Does it Have an Impact?
}

\author{
Tarek Sabet ${ }^{1}$, Amany Elbanna ${ }^{1}$, Essam El-Din Bedewy ${ }^{2}$, \\ Mohamed Abozamel $^{3}$,Shwikar Abdel Salam ${ }^{4}$, Ayman Shamsya ${ }^{1}$ \\ ${ }^{1}$ Department of Internal Medicine, Faculty of Medicine, University of Alexandria, \\ Egypt. \\ ${ }^{2}$ Department of Tropical Medicine \& amp; Hygiene, Faculty of Medicine, University \\ Of Alexandria ,Egypt. \\ ${ }^{3}$ Specialist of Internal Medicine, Alexandria University Students' Hospital,Egypt. \\ ${ }^{4}$ Department of Medical Microbiology \& Immunology, Faculty of Medicine, University \\ of Alexandria, Egypt.
}

Corresponding Author Bedewy, Essam ElDin

Mobile:

00201100771111

\section{E-mail:}

essambedewyclinic@g mail.com

Key words:

Clostridium Difficile, inflammatory bowel disease, ulcerative colitis, Crohn's disease
Background and study aim: Limited data exist on outcomes in inflammatory bowel disease (IBD) patients who develop Clostridium Difficile infection (CDI). The aim of the study to investigate prevalence of CDI in IBD with assessment of the disease behavior in affected patients.

Patients and Methods: 30 IBD patients and 15 healthy subjects of matched age \& sex as control group. Patient were classified into two groups; group I (15 patients with Crohn's disease), group II (15 patients with ulcerative colitis) \& control group (15 Patients not having IBD). Disease activity for group I was determined by Crohn's disease activity index (CDAI) \& for group II by Truelove $\&$ Witts score. All patients \& controls underwent Computed Tomography Enterocolongraphy, ileo-colonoscopy with ileal \& colonic biopsies, and Clostridium Difficile detection \& quantification plus detection of toxin A $\&$ B using SYBR Green Real-time PCR.

Results: 3 patients from group I had CDI and these 3 patients had active disease, one with severe activity (CDAI 550) and two with moderate activity (CDAI 380 \& 420). Also 3 patients from group II had $\mathrm{CDl}$ and these 3 patients had moderate activity. Only one patient from the control group had CDI carriage (non-toxin producing strain).The rest of patients (38 patients) had no CDI (of them, one patient had mildly active Crohn's disease with CDAI of $200 \&$ two patients had mildly active ulcerative colitis $\&$ the others were in remission).

Conclusion: Prevalence of toxigenic CDI was $20 \%$ among IBD patients and significantly associated with disease activity.

\section{INTRODUCTION}

Idiopathic inflammatory bowel disease (IBD) [Crohn's disease (CD) and ulcerative colitis (UC)] is a chronic or relapsing inflammatoryimmune related gut disease. These two forms of IBD share epidemiologic and clinical characteristics, suggesting an underlying similar etiology [1].

There is wide geographic variability in incidence and prevalence of IBD. Higher incidence rates were observed in England, Northern Europe, United States and Canada with lower incidence in Asia-Pacific region, with exception of Australia [2].

The clinical manifestations of $\mathrm{CD}$ are more variable than $\mathrm{UC}$; this may be due to transmural involvement and variability of disease extent in $C D$ in comparison to the more superficial \& less extensive distribution of UC [3].

European Colitis \& Crohn's Organization (ECCO) stated that disease extent is the main influencer on treatment modality and determinant to surveillance frequency [4]. 
Diagnosis should be confirmed by clinical evaluation with combination of biochemical, endoscopic, histological \&/or radiological investigations $[4,5]$.

ECCO stated: For suspected CD, ileocolonoscopy with biopsies from terminal ileum and colonic segment for microscopic evidence of $\mathrm{CD}$ are first line procedures to establish diagnosis. ${ }^{(5)}$ However in UC, colonoscopy with ileal intubation together with segmental biopsies including rectum is a main corner stay to establish diagnosis and disease extent [4].

Clostridium Difficile infection (CDI) is defined as acute diarrheal disease caused mainly by toxigenic CDI strain [6]. Clostridium Difficile (C. Difficile) was first described as a cause of pseudomembranous colitis in 1978, mainly an antibiotic-associated infection [7]. Evidences suggested that in a process similar to that in CDI, microbial dysbiosis, consisting of an increase of detrimental bacterial populations and their toxic metabolites, together with a decrease in beneficial bacteria and their metabolic end products, alter gut luminal environment and contribute to IBD pathogenesis [8].

IBD patients have increased risk of acquiring $\mathrm{CDI}$, have higher rates of recurrence and worse outcome. C. Difficile was associated with IBD but understanding the relationship between the two conditions is confusing. However, it is unclear how these two dysbiosis-related conditions may interact with each other, and whether, there exists a cause-consequence versus concurrent relationship $[\mathbf{9 , 1 0}]$.

Lower abdominal pain and tenderness and watery diarrhea are typical CDI symptoms. With underlying active IBD, diarrhea can be frequently bloody [11]. Patients may have fever, malaise, anorexia, and leukocytosis with left shift, hypoalbuminemia and increased stool leukocytes. These findings can be seen in both CDI and IBD exacerbations, thus usually distinguish between these two conditions on the basis of laboratory testing or symptoms alone are difficult [9].

The nucleic acid amplification tests (NAATs) for C-Difficile toxin genes as PCR are superior to toxins A \& B enzyme immunoassay (EIA) as stated by American College of Gastroenterology (ACG) in 2013 [12].

ACG guidelines in 2013 strongly recommend that all patients with IBD hospitalized with a disease flare should undergo testing for CDI. In addition ambulatory patients with IBD who develop diarrhea and known to have quiescent disease should be tested, or in the presence of risk factors such as recent hospitalization or antibiotic use [12].

Limited data exist on outcomes in IBD patients who develop CDI. Most of the evidence indicates that, compared to the general population, IBD patients with CDI have worse clinical outcomes [9].

Aim of the work: Investigate prevalence of CDI in IBD (CD \& UC) with assessment of the disease behavior in affected patients.

\section{PATIENTS AND METHODS}

30 newly diagnosed (naïve) patients with IBD (according to clinical, laboratory, radiological, endoscopic \& histopathological findings) \& 15 healthy controls of matched age \& sex were included in this cross-sectional study.

Only newly diagnosed patients (in our endoscopy unit) were enrolled in this study. Inclusion criteria included only newly diagnosed UC / CD adult patients of both sex who were able to give consent to participate in the study. Exclusion criteria were pervious diagnosed IBD \&/or patients receiving any related drugs (5-ASA, immunosuppressants, biologics or broad spectrum antibiotics), surgical intervention or hospital admission within the past three months

These patients were further classified into three groups: group I: 15 patients with CD, group II: 15 patients with UC, \& group III: 15 healthy control persons confirmed, not having IBD or diarrhea within the past three months.

Activity was assessed clinically for Crohn's disease by using Crohn's disease activity index (CDAI) ${ }^{[13]} \&$ for Ulcerative colitis patients by using Truelove and Witts Classification of Ulcerative Colitis [4].

$\mathrm{CBC}$, serum albumin, C-reactive protein (CRP), erythrocyte sedimentation rate (ESR), stool cultures (for exclusion of any concurrent bacterial infection of gut) \& fecal calprotectin were done to all patients $\&$ controls.

All patients underwent Computed Tomography Enterocolongraphy \& ileo-colonoscopy with mucosal biopsies for histopathological assessment. 
Stool specimens from patients \& controls were collected immediately upon defecation, kept in freezer, and delivered immediately to our laboratory frozen, where aliquots of each specimen were frozen at $-80{ }^{\circ} \mathrm{C}$ until DNA extraction was done. DNA was extracted from $150 \mathrm{mg}$ stool samples using ISOLATE Fecal DNA Kit (Bioline, UK). The DNA was then bound, isolated and purified using spin columns. The resulting DNA extracts were stored at $-70^{\circ} \mathrm{C}$ until PCR assessment. Oligonucleotide primers were targeted at the 16SrRNA gene (rDNA) sequences of C. Difficile (Metabion International AG. Germany). Amplification was performed in a light cycler (Rotor Gene Q, Qiagen, Germany) using a SensiFAST TM SYBR No-ROX PCR kit (Bioline Co. UK) [14-16].

\section{RESULTS}

The study was done between January 2016 to December 2017 on 30 patients \& 15 controls, no significant differences were observed between the three groups as regards the demographic data [Table (1)].

Four patients from group (I) (26.6\%) and five (33.3\%) from Group (II) were in active state (as assessed by using Crohn's disease activity index (CDAI) \& Truelove and Witts Classification of Ulcerative Colitis, while eleven (73.3\%) patients from the group (I) and ten $(66.7 \%)$ patients within the group (II) were quiescent. The patients with active disease in group (I) were distributed as 1 patient with mild disease activity, 2 patients with moderate disease activity and 1 patient with severe disease activity, according to CDAI while the patients with active disease from group (II) were distributed as 2 patients with mild disease activity and 3 patients with moderate disease activity but no patients recorded with severe disease activity, according to Truelove and Witts classification [Table (2)].

From group (I), the patient with severe disease activity had extra-intestinal manifestations (EIMs) (uveitis \& erythema nodosum) \& the two patients with moderate disease activity had arthritis, while the patient with mild disease activity as well as the 11 quiescent patients had no EIMs. Similarly from group (II), two patients with moderate disease activity had arthritis (one of them had episcleritis as well), one more patient with moderate disease activity had episcleritis, while the two with mild disease activity as well as the 10 patients in quiescent status had no EIMs [Table (3)].

In Group (I): 3 patients within Crohn's disease group had CDI and these 3 patients had active disease, 1 of them had severe disease activity and 2 had moderate disease activity. The patient with mild disease activity in addition to the rest 11 patients, which were in quiescent state, had no CDI. The patient with severe disease from group (I) had Fecal calprotectin level of 830, CDAI of 550, C. Difficile PCR replication count of 1.27 X $10^{-4}$ and production of Both toxin A and B. First Patient with moderate disease from group (I) had fecal calprotectin level of 218, CDAI of 380, C. Difficile PCR replication count of $1.34 \times 10^{-6}$ and production of toxin B only. Second Patient with moderate disease from group (I) had fecal calprotectin level of 280, CDAI of 420, C. Difficile PCR replication count of $2.4 \times 10^{-6}$ and production of toxin $\mathrm{B}$ only. Patient with mild disease from group (I) had fecal calprotectin level of 112, CDAI of 200 and had no C. Difficile infection [Table (4)].

In Group (II): 3 patients within Ulcerative colitis group had CDI and these 3 patients had moderate active disease, the 2 patients with mild disease activity in addition to the patients in quiescent state, had no CDI. First patient with moderate disease from group (II) had fecal calprotectin level of 325 , C. Difficile PCR replication count of $1.49 \times 10^{-6}$ and production of toxin B only. Second patient with moderate disease from group (II) had fecal calprotectin level of 465, C. Difficile PCR replication count of $2.37 \times 10^{-6}$ and production of toxin B only. Third patient with moderate disease from group (II) had Fecal calprotectin level of 902, C. Difficile PCR replication count of $1.85 \times 10^{-4}$ and production of Both toxin A and B. First patient with mild disease from group (II) had fecal calprotectin level of 85 and had no CDI. Second patient with mild disease from group (II) had fecal calprotectin level of 97 and no CDI [Table (5)].

In control Group: only 1 subject was found to have C. Difficile carriage within the control group. The C. Difficile carrier within the control group had negative fecal calprotectin level of 42 and Cl. Difficile PCR replication counts of 1.47 $\mathrm{x}$ 10-7, the bacteria were non-toxin producer [Table (6)]. 
Table (1): Comparison between the three studied groups according to demographic data.

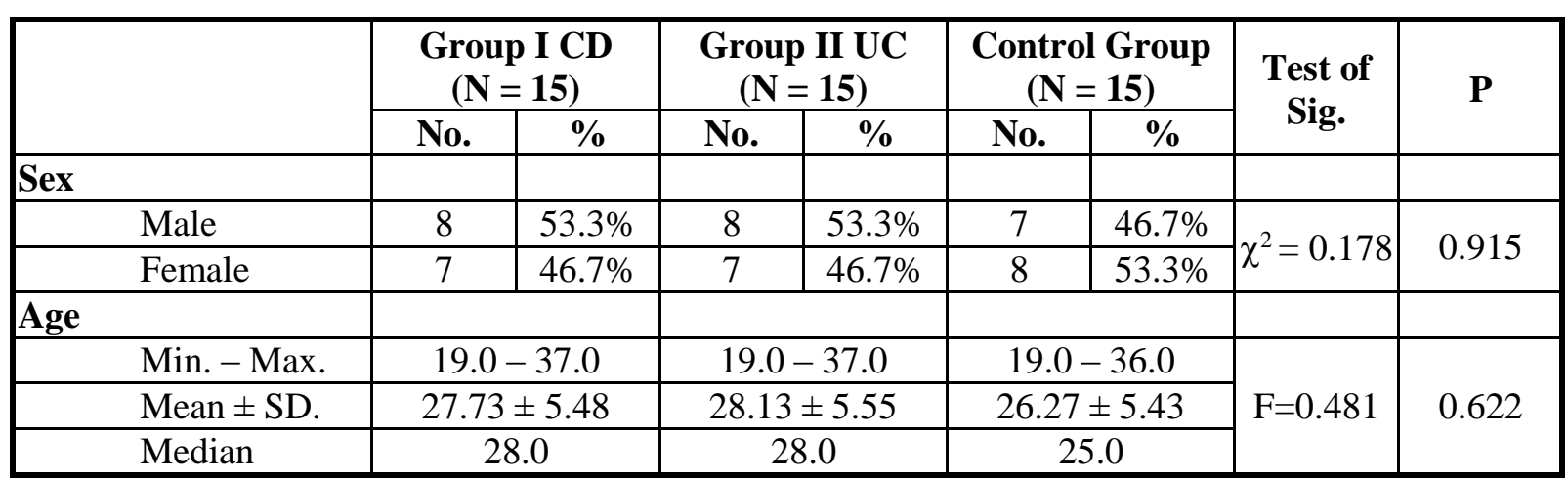

$\chi^{2}$, $\mathrm{p}: \chi^{2}$ and $\mathrm{p}$ values for Chi square test for comparing between the three groups

$\mathrm{F}$ and $\mathrm{P}$ values for ANOVA test

Table (2): Distribution of the studied cases according to clinical activity.

\begin{tabular}{|l|c|c|c|c|}
\hline \multirow{2}{*}{ Disease status } & \multicolumn{2}{|c|}{$\begin{array}{c}\text { Group I CD } \\
(\mathbf{N}=\mathbf{1 5})\end{array}$} & \multicolumn{2}{c|}{$\begin{array}{c}\text { Group II UC } \\
(\mathbf{N = 1 5})\end{array}$} \\
\cline { 2 - 5 } & No. & $\mathbf{\%}$ & No. & \% \\
\hline In remission & 11 & $73.33 \%$ & 10 & $66.67 \%$ \\
\hline Mild disease & 1 & $6.67 \%$ & 2 & $13.33 \%$ \\
\hline Moderate disease & 2 & $13.33 \%$ & 3 & $20 \%$ \\
\hline Sever disease & 1 & $6.67 \%$ & 0 & $0 \%$ \\
\hline
\end{tabular}

Table (3): Extra-intestinal manifestation of IBD among patients of groups I \& II.

\begin{tabular}{|c|c|c|c|}
\hline $\begin{array}{c}\text { Extra-intestinal } \\
\text { manifestations (EIMs) }\end{array}$ & Number of patients & $\%$ & Clinical activity \\
\hline \multicolumn{4}{|l|}{ Group I CD (n=15) } \\
\hline No EIMs. & 12 & $80 \%$ & Remission + mild \\
\hline Arthritis & 2 & $13.33 \%$ & Moderate \\
\hline Ocular EIM & 1 (Uveitis) & $6.67 \%$ & Severe \\
\hline Cutaneous EIM & 1 (erythema nodosum) & $6.67 \%$ & $\begin{array}{c}\text { Severe (same patient with ocular } \\
\text { EIM) }\end{array}$ \\
\hline \multicolumn{4}{|l|}{ Group II UC (n=15) } \\
\hline No EIMs. & 12 & $80 \%$ & Remission + mild \\
\hline Arthritis & 2 & $13.33 \%$ & Moderate \\
\hline Ocular & 2 (episcleritis) & $13.33 \%$ & $\begin{array}{c}\text { Moderate (one patient in common } \\
\text { with arthritis) }\end{array}$ \\
\hline Cutaneous EIM & 0 & $0 \%$ & \\
\hline
\end{tabular}

Table (4): Distribution of the studied clinically active cases of Group I according to CDAI, Fecal calprotectin, Clostridia Difficile Count and Toxins production.

\begin{tabular}{|l|c|c|c|c|c|c|c|c|}
\hline & Case 1 & Case 2 & Case 3 & Case 4 & Min & Max & Med. & Mean \\
\hline CDAI & 200 & 380 & 420 & 550 & 200 & 550 & 387.5 & $394.3 \pm 65.3$ \\
\hline $\begin{array}{l}\text { Fecal } \\
\text { Calprotectin }\end{array}$ & 112 & 218 & 280 & 830 & 112 & 830 & 390 & $412 \pm 38.32$ \\
\hline $\begin{array}{l}\text { Clostridia } \\
\text { Difficile count }\end{array}$ & Negative & $1.34 \times 10^{-6}$ & $2.4 \times 10^{-6}$ & $1.27 \times 10^{-4}$ & $1.34 \times 10^{-6}$ & $1.27 \times 10^{-4}$ & $1.67 \times 10^{-5}$ & $1.67 \pm 0.32 \times 10^{-5}$ \\
\hline $\begin{array}{l}\text { Clostridia } \\
\text { difficile toxin }\end{array}$ & $\begin{array}{c}\text { A-ve/B- } \\
\text { ve }\end{array}$ & A-ve/B+ve & A-ve/B+ve & A+ve/B+ve & - & - & - & - \\
\hline$P_{c}$ value & & & & 0.0063 & & & & \\
\hline
\end{tabular}

$P_{c}$ value positive if $\leq 0.05$ i.e.: $p$ value for individualized comparison. 
Table (5): Distribution of the studied clinically active cases of Group II according to True and Love activity index, fecal calprotectin, Clostridia Difficile PCR replication count and production of toxins.

\begin{tabular}{|c|c|c|c|c|c|c|c|c|c|}
\hline & Case 1 & Case2 & Case 3 & Case 4 & Case 5 & Min & Max & Med. & Mean \\
\hline $\begin{array}{l}\text { Disease } \\
\text { activity }\end{array}$ & MILD & MILD & MOD & MOD & MOD & - & - & 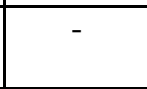 & - \\
\hline \begin{tabular}{|l|} 
Fecal \\
Calprotectin
\end{tabular} & 85 & 97 & 325 & 465 & 902 & 85 & 902 & 375 & $399 \pm 22.32$ \\
\hline \begin{tabular}{|l|} 
Clostridia \\
Difficile \\
count
\end{tabular} & Negative & Negative & $1.49 \times 10^{-6}$ & $2.37 \times 10^{-6}$ & $1.85 \times 10^{-4}$ & $1.49 \times 10^{-6}$ & $1.85 \times 10^{-4}$ & $1.93 \times 10^{-5}$ & $\begin{array}{c}1.99 \pm 0.64 \\
\times 10^{-5}\end{array}$ \\
\hline $\begin{array}{l}\text { Clostridia } \\
\text { difficile } \\
\text { Toxin }\end{array}$ & - & - & $\begin{array}{l}\text { A-ve/ } \\
\text { B+ve }\end{array}$ & $\begin{array}{l}\text { A-ve/ } \\
\text { B+ve }\end{array}$ & $\begin{array}{l}\text { A+ve/ } \\
\text { B+ve }\end{array}$ & - & - & - & - \\
\hline$P_{c}$ value & \multicolumn{9}{|c|}{0.0047} \\
\hline
\end{tabular}

$\mathrm{P}_{\mathrm{c}}$ value positive if $\leq 0.05$ i.e.: $\mathrm{p}$ value for individualized comparison.

Table (6): Comparison between all cases of the three studied groups according to Presence of Clostridia Difficile.

\begin{tabular}{|c|c|c|c|c|c|c|}
\hline & \multicolumn{2}{|c|}{$\begin{array}{l}\text { Group I CD } \\
(\mathbf{N}=15)\end{array}$} & \multicolumn{2}{|c|}{$\begin{array}{c}\text { Group II UC } \\
(\mathbf{N}=15)\end{array}$} & \multicolumn{2}{|c|}{$\begin{array}{c}\text { CONTROL GROUP } \\
(N=15)\end{array}$} \\
\hline & No. & $\%$ & No. & $\%$ & No. & $\%$ \\
\hline \multicolumn{7}{|l|}{ Clostridia Difficile } \\
\hline Negative & 12 & 80.0 & 12 & $80.0 \%$ & 14 & $93.33 \%$ \\
\hline Positive & 3 & $20.0 \%$ & 3 & $20.0 \%$ & 1 & $6.67 \%$ \\
\hline $\begin{array}{l}\text { Relation to disease clinical activity } \\
(\mathbf{N}=3)\end{array}$ & 3 & $100 \%$ & 3 & $100 \%$ & - & - \\
\hline Mild & 0 & $0 \%$ & 0 & $0 \%$ & - & - \\
\hline Moderate & 2 & $66.7 \%$ & 3 & $100 \%$ & - & - \\
\hline Sever & 1 & $33.3 \%$ & 0 & $0 \%$ & & \\
\hline
\end{tabular}

\section{DISCUSSION}

IBD patients have a risk for developing special enteric infection more than general population especially CDI. IBD itself is an independent risk factor for CDI: a threefold increased risk over general population has been reported. ${ }^{[1]}$ Analysis of a registry database suggests that $10 \%$ of IBD patients will develop a CDI at some point, and in approximately $10 \%$ of patients, CDI occurs at time of IBD diagnosis [18].

According to CDAI, most Group I patients were in clinical remission $(73.33 \%)$, those with active disease, $6.67 \%$ have severe disease activity, $13.33 \%$ have moderate disease activity and $6.67 \%$ have mild disease activity. Crohn's disease activity index (CDAI) used as index for the $\mathrm{CD}$ assessment $[13,19-21]$.

Regarding Truelove and Witts classification, most Group II patients (66.67\%) were in clinical remission, $20 \%$ of patients had moderate disease activity and $13.33 \%$ had mild disease activity but no patients had severe disease activity.

Prevalence of Clostridium Difficile infection among patients' groups was $20 \%$ for both CD and UC groups and $6.67 \%$ for control group. All patients in both groups with CDI were in activity. Only patients in both groups showing mild disease activity were negative for Clostridium Difficile infection.

Those with severe disease activity within CD group have highest level of Clostridium Difficile relative count $1.27 \times 10^{-4}$ with production of both cytotoxic toxin A and B and highest level of fecal calprotectin 830 .

While UC patients, highest Clostridium Difficile count $1.85 \times 10^{-4}$ was found in patients with moderate disease activity with highest fecal calprotectin level of 902. Infection was associated with production of both toxin $\mathrm{A}$ and B. 
Other two Clostridium Difficile count were $2.37 \times 10^{-6} \& 1.49 \times 10^{-6}$ related to moderate disease activity but less active than patient with highest Clostridium Difficile count, with fecal calprotectin of 465 and 325 respectively of these patients and production of only toxin B.

The only one healthy control with Clostridium Difficile carriage has Clostridium Difficile relative count of $1.47 \times 10^{-7}$ and his bacteria were non-toxin producers. Comparing this control Clostridium Difficile count with mean of Clostridium Difficile count of other IBD groups $\left[1.67 \pm 0.32 \times 10^{-5}\right.$ for $\mathrm{CD}$ group and $1.99 \pm 0.64$ $\mathrm{x} 10^{-5}$ for UC group], A strong significant statistical difference regarding Clostridium Difficile count of both groups versus control Clostridium Difficile relative count was noted. i.e. $\mathrm{P}^{3}=0.00012$.

Issa et al. [22] showed $16 \%$ prevalence of CDI among IBD patients and $50 \%$ of infected patients were hospitalized and concluded that CDI is significantly increased in IBD patients and negatively impacted clinical outcome.

Balamurugan et al [23] found that the prevalence of CDI was so high to the level that 34 patient from the 37 patients with UC had CDI and also 21 form healthy controls were positive to CDI, but only 8 patients from UC group \& none from controls were toxin producer, no statistical significant difference between active and quiescent disease was found. In contrast to the present study, this could be attributed to most patients in Indian study have non toxinproducing infection and for complete pathognomonic action of CDI to occur, toxin production is mandatory.

Gwen et al [24] study found no statistical difference regarding CDI and disease activity. They stated that $10 \%$ of IBD flares reported to be result of microbial pathogen invasion, and testing CDI is mandatory.

Thus ECCO in 2013, strongly recommended CDI testing in any IBD patient presented with disease flare at any time during disease course $[12,18]$.

Ananthakrishnan et al studied the impact of CDI on IBD and documented an increase in incidence among those with underlying IBD and substantial morbidity association, the surgical need and even mortality. Also, they mentioned similarity of clinical presentation between CDI and a flare of underlying IBD that highlighted the importance of diagnosis as essential mean to prevent deterioration and further need for immunosuppression escalation in absence of appropriate antibiotic therapy [25].

In 2017, Gillespie et al investigated epidemiology and risk factors of CDI in patients with IBD. Their results showed that incidence of CDI among IBD patients was $6.7 \%$ with equal prevalence of CDI among $\mathrm{CD}$ and $\mathrm{UC}$, concluding that IBD patients are more vulnerable to CDI at a younger age and that IBD patients with CDI would require biologic therapy with increased rates of extra-intestinal manifestations. [26] These results are in agreement with our results, where some patients with both IBD \& CDI had extra-intestinal manifestations (arthritis, uveitis, episcleritis or erythema nodosum).

Shoaei et al in 2015 stated that the prevalence of C. Difficile isolates was $31.8 \%(27 / 85)$ in UC patients and rather prevalent in UC patients \& all patients with CDI experienced moderate to severe disease and so need for close monitoring and appropriate treatment including early detection and treatment of CDI would lead to better UC outcomes [27]. These results are matching with results of this study.

AGA (2017) conducted an expert review from the clinical practice updates on management of CDI in IBD and recommended that clinicians should test patients who present with a flare of underlying IBD for CDI, consider hospitalization for close monitoring and aggressive management for IBD with CDI who have profuse watery \&/or bloody diarrhea, severe abdominal pain, markedly increased peripheral leukocyte count, or evidence of sepsis and referral for fecal microbiota transplantation to IBD patients with recurrent CDI [28].

Kim et al concluded that CDI was not that rare cause of flare-up in patients with UC in Korea. However, CDI did not appear to influence the course of UC flare-up among Korean patients [29].

D'Aoust $\mathrm{J}$ et al identified 70 articles including a total of 932141 IBD patients or IBD-related hospitalizations, reporting that in IBD, CDI could be associated by increased morbidity, with subsequent escalation in IBD medical therapy, urgent colectomy and increased hospitalization, as well as excess mortality [30]. 


\section{CONCLUSION}

IBD has been found to be associated with CDI. The prevalence of toxigenic CDI was $20 \%$ among studied IBD patients and significantly associated with initial disease activity.

\section{RECOMMENDATIONS}

Further investigations about the trigger of IBD associated with CDI are needed. Also more research is needed including larger number of patients to show the impact of immunosuppressant as part of treatment of IBD on vulnerability to $\mathrm{CDI}$.

Ethical approval and informed consent: The Ethics Review Board of the Faculty of Medicine, Alexandria University, approved the study. Informed consent was obtained from all patients.

Funding: Non-identified

Competing interests: The authors declare they have neither financial nor non-financial competing interests

\section{REFERENCES}

1. Fledman, Sleisenger and Fordtrans. Gastrointestinal and Liver Disease.8th ed. Canada Saunders, Elservier 2006; 2499-549.

2. NG SC, Tang W, Ching JY. Incidence and phenotype of inflammatory bowel disease based on results from the Asia-Pacific Crohn's and Colitis Epidemiology Study. Gastroenterology 2013; 145: 158-165 e2.

3. Peppercorn MA, Martins NB. Inflammatory bowel disease. Am J Manag Care 2004; 10(8): 544-52.

4. Magro F, Gionchetti P, Eliakim R. Third European Evidence-based Consensus on Diagnosis and Management of Ulcerative Colitis. Part 1: Definitions, Diagnosis, Extraintestinal Manifestations, Pregnancy, Cancer Surveillance, Surgery, and Ileo-anal Pouch Disorders. J Crohns Colitis 2017; Feb 2.

5. Gomollón F, Dignass A, Annese V. 3rd European Evidence-based Consensus on the Diagnosis and Management of Crohn's Disease 2016: Part 1: Diagnosis and Medical Management. J Crohn's Colitis 2017; 11 (1): 325.
6. Cohen SH, Gerding DN, Johnson S. Clinical practice guidelines for Clostridium difficile infection in adults: 2010 update by the Society for Healthcare Epidemiology of America (SHEA) and the Infectious Diseases Society of America (IDSA). Infect Control and Hosp Epidemiol 2010; 3:431-55.

7. Bartlett JG, Chang TW, Gurwith M. Antibioticassociated pseudomembranous colitis due to toxin-producing clostridia. N Engl J Med 1978; 298(10): 531-4.

8. Tamboli CP, Neut C, Desreumaux P, Colombel JF. Dysbiosis in inflammatory bowel disease. Gut 2004; 53(1): 1-4.

9. Tang YM, \& Stone CD. Clostridium difficile infection in inflammatory bowel disease: challenges in diagnosis and treatment. Clin $J$ Gastroenterol 2017; 10(2): 112-123.

10. Nitzan O, Elias M, Chazan B. Clostridium difficile and inflammatory bowel disease: role in pathogenesis and implications in treatment. World J Gastroenterol 2013; 19(43): 7577-85.

11. Bartlett JG, \& Gerding DN. Clinical recognition and diagnosis of Clostridium difficile infection. Clin Infect Dis 2008; 46(Suppl 1): S12-8.

12. Surawicz CM, Brandt LJ, Binion DG. Guidelines for diagnosis, treatment, and prevention of Clostridium difficile infections. Am J Gastroenterol 2013; 108(4): 478-98; quiz 499.

13. Elliott P, Lennard-Jones J, Hathway N. "Simple index of Crohn's disease activity." Lancet 1999; (8173): 876-890.

14. Balamurugan R, Janardhan HP, George S, Raghava MV, Muliyil J \& Ramakrishna BS. Molecular studies of fecal anaerobic commensal bacteria in acute diarrhea in children. $J$ Pediatr Gastr Nutr 2008; 46: 514-9.

15. Nadkarni, MA, Martin FE, Jacques NA, \& Hunter N. Determination of bacterial load by real-time PCR using a broad-range (universal) probe and primers set. Microbiology 2002; 148:257-66.

16. Penders J, Vink C, Driessen C, London N, Thijs C, Stobberingh EE. Quantification of Bifidobacterium spp., Escherichia coli and Clostridium difficile in faecal samples of breastfed and formula-fed infants by real-time PCR. FEMS Microbiol Lett 2005; 243:141-7. 
17. Rodemann JF, Dubberke ER, \& Reske KA. Incidence of Clostridium difficile infection in inflammatory bowel disease. Clin Gastroenterol Hepatol 2007; 5:339-44.

18. Binion DG. Clostridium difficile infection in patients with inflammatory bowel disease. Gastroenterol Hepatol 2012; 8(9): 615-7.

19. Gomollón F, Dignass A, Annese V. 3rd European Evidence-based Consensus on the Diagnosis and Management of Crohn's Disease 2016: Part 1: Diagnosis and Medical Management. J Crohns Colitis 2017; 11(1): 325.

20. Yoshida E. "The Crohn's Disease Activity Index, its derivatives and the Inflammatory Bowel Disease Questionnaire: a review of instruments to assess Crohn's disease". Can J Gastroenterol 1999; 13 (1): 65-73.

21. Acciuffi S, Ghosh S, \& Ferguson A. "Strengths and limitations of the Crohn's disease activity index, revealed by an objective gut lavage test of gastrointestinal protein loss". Aliment Pharmacol Ther 1996; 10 (3): 321-6.

22. Issa M, Vijayapal A, \& Graham MB. Impact of Clostridium difficile on inflammatory bowel disease. Clin Gastroenterol Hepatol 2007; 5(3): 345-51.

23. Balamurugan R, Balaji V, \& Ramakrishna BS. Estimation of faecal carriage of Clostridium difficile in patients with ulcerative colitis using real time polymerase chain reaction. Indian $J$ Med Res 2008; 127(5): 472-7.
24. Masclee GM, Penders J, \& Jonkers DM. Is clostridium difficile associated with relapse of inflammatory bowel disease? Results from a retrospective and prospective cohort study in the Netherlands. Inflamm Bowel Dis 2013; 19(10): 2125-31

25. Ananthakrishnan AN \& Binion DG. Impact of Clostridium difficile on Inflammatory Bowel Disease. Expert Rev Gastroenterol Hepatol 2010; 4(5): 589-600.

26. Gillespie W, Marya N, Fahed J, Leslie G, Patel $\mathrm{K}$, \& Cave D. Clostridium difficile in Inflammatory Bowel Disease: A Retrospective Study. Gastroenterology Research and Practice; Volume 2017, Article ID 4803262

27. Shoaei P, Shojaei H, Jalali M, Khorvash F, Hosseini SM, Ataei B, et al. Clostridium difficile isolated from faecal samples in patients with ulcerative colitis. BMC Infectious Diseases 2019; 19:361

28. Khanna S, Shin A, \& Kelly CP. Management of Clostridium difficile Infection in Inflammatory Bowel Disease: Expert Review from the Clinical Practice Updates. Committee of the AGA Institute. Clinical Gastroenterology and Hepatology 2017; 15:166-174

29. Kim DB, Lee KM, Park SH, Kim YS, Kim ES, Lee $\mathrm{J}$, et al. Is Clostridium difficile infection a real threat in patients with ulcerative colitis? A prospective, multicenter study in Korea. Intest Res 2018; 16(2): 267-272

30. D'Aoust J, Battat R, Bessissow T. Management of inflammatory bowel disease with Clostridium difficile infection. World J Gastroenterol 2017 July 21; 23(27): 4986-5003s. 